\title{
Avaliação dos impactos sociais, de custo/benefício e custo/eficácia do Programa Vira Vida (ciclo 2012 - 2014)
}

Miguel Barbosa Fontes ${ }^{1}$ Rodrigo Campos Crivelaro ${ }^{2}$

Cleude Gomes da Silva ${ }^{3}$ Eliane Lopes Noronha Campos ${ }^{4}$ Rafael Fujioka ${ }^{5}$

1 Ph.D em Saúde Pública e Mestre em Desenvolvimento Econômico da América Latina pela Johns Hopkins University. Diretor da John Snow do Brasil Consultoria.

2 Mestre em Gestão Social e Trabalho pelo Departamento de Administração e doutorando pelo Programa de Pós-graduação em Desenvolvimento, Sociedade e Cooperação Internacional da Universidade de Brasília (UnB).Gerente de Projetos da John Snow Brasil Consultoria.

3 Graduada em Psicologia pelo Centro Universitário de Brasília (Uniceub). Coordenadora Nacional do Programa Vira Vida.

4 Graduada em Pedagogia pelo Centro Universitário do Distrito Federal (Unidf). Assessora técnica do Conselho Nacional do SESI.

5 Graduando em Administração de Empresas pela Universidade Católica de Brasília (UCB). Assistente de pesquisa da 
SEGUNDO O UNICEF, UM MILHÃO DE CRIANÇAS NO MUNDO SÃO DIRETAMENTE AFETADAS PELA VIolÊnCia SEXual. Praticamente um terço dos Casos ocorre no Brasil. O Programa VIRA VIDA RESGATA ADOLESCENTES E JOVENS NESTA SITUAÇÃO, PROPORCIONANDO ATENDIMENTO PSICOLÓGICO, EDUCACIONAL E PROFISSIONALIZANTE, INCLUINDO INSERÇÃO E ACOMPANHAMENTO NO MERCADO DE TRABALHO. PARA AVALIAR O IMPACTO DO PROGRAMA, TRÊS ANÁLISES FORAM REALIZADAS: FINANCEIRA, ECONÔMICA E SOCIAL. UM ESTUDO GRUPO CONTROLE FOI REALIZADO EM 2014, EM 19 ESTADOS BRASILEIROS, COM MARGEM DE ERRO DE 2,7\% (N=1.227). UM OUUESTIONÁRIO FOI GERADO A PARTIR DA ANÁLISE DE CONSISTÊNCIA E VALIDADE DE UMA ESCALA DE CONHECIMENTOS, ATITUDES E PRÁTICAS (CAP), DE -65 A 65 PONTOS, DIVIDIDOS EM OUATRO DIMENSÕES: VALORES DO TRABALHO, EDUCAÇÃO, LAÇOS FAMILIARES E COMUNITÁRIOS E DESENVOLVIMENTO HUMANO. UTILIZARAM-SE REGRESSÕES AJUSTADAS PARA IDENTIFICAR DIFERENÇAS ENTRE GRUPOS. O TESTE ALFA DE CRONBACH ALCANÇOU 0,87. OS RESULTADOS MOSTRARAM OQUE O CUSTO TOTAL POR ALUNO CHEGOU A R\$ 1.973,99 POR MÊS. CADA R\$ 1,00 INVESTIDO PELO PROGRAMA GEROU UM AUMENTO DE R\$ 1,74 NA RENDA INDIVIDUAL DO JOVEM. O VIRA VIDA AUMENTOU OS NÍVEIS DE CAP PARA VALORES DE TRABALHO, EDUCAÇÃO E DESENVOLVIMENTO HUMANO, MAS NÃO PARA LAÇOS FAMILIARES E COMUNITÁRIOS. A ESCALA UTILIZADA MOSTROU-SE UMA MEDIDA CONFIÁVEL PARA MENSURAR AS MUDANÇAS DE CAP DE JOVENS EXPLORADOS SEXUALMENTE. SUGERE-SE REVISÃO DAS ABORDAGENS PARA FORTALECER LAÇOS FAMILIARES E COMUNITÁRIOS.

\section{Abstract}

ACCORDING TO UNICEF, ONE MILLION CHILDREN WORLDWIDE ARE DIRECTLY AFFECTED BY SEXUAL VIOLENCE. NEARLY A THIRD OF ALL CASES OCCUR IN BRAZIL. VIRAVIDA PROGRAM SUPPORTS VULNERABLE TEENAGERS AND YOUNGSTERS UNEMPLOYED ACROSS THE COUNTRY, PROVIDING PSYCHOLOGICAL, EDUCATIONAL AND VOCATIONAL ASSISTANCE, INCLUDING PLACING AND MONITORING IN THE LABOR MARKET. TO ASSESS THE IMPACT OF THE PROGRAM, THREE ANALYZES WERE PERFORMED: FINANCIAL, ECONOMIC AND SOCIAL. A CONTROL GROUP STUDY WAS CONDUCTED IN 2014 IN 19 BRAZILIAN STATES WITH A MARGIN OF ERROR OF $2.7 \%(N=1,227)$. QUESTIONNAIRE WAS GENERATED FROM THE ANALYSIS OF THE CONSISTENCY AND VALIDITY OF A SCALE OF KNOWLEDGE, ATTITUDES AND PRACTICES (KAP) OF -65 TO 65 POINTS, DIVIDED INTO FOUR DIMENSIONS: VALUES OF LABOR, EDUCATION, FAMILY AND COMMUNITY TIES AND HUMAN DEVELOPMENT. ADJUSTED REGRESSIONS WERE USED TO IDENTIFY DIFFERENCES BETWEEN GROUPS. THE CRONBACH ALPHA TEST REACHED 0.87. RESULTS DEMONSTRATED THAT THE TOTAL COST PER STUDENT REACHED R\$ 1.973,99 PER MONTH. EVERY RS 1.00 INVESTED IN THE PROGRAM GENERATED AN INCREASE IN INDIVIDUAL INCOME YOUTH OF R\$ 1.74. THE VIRAVIDA INCREASED LEVELS OF CAP VALUES FOR THE DIMENSIONS OF LABOR, EDUCATION, AND HUMAN DEVELOPMENT, BUT NOT FAMILY AND COMMUNITY TIES. THE SCALE USED DEMONSTRATED TO BE A RELIABLE MEASURE TO ASSESS CHANGES IN KAP SEXUALLY EXPLOITED YOUTH. A REVIEW OF APPROACHES TO STRENGTHENING FAMILY AND COMMUNITY TIES AND VALUES IS SUGGESTED.

\section{PALAVRAS-CHAVE:}

Avaliação de impacto; Adolescentes e jovens; Exploração sexual.

Revista Brasileira de Monitoramento e Avaliação | Número 9 | Janeiro-Junho de 2015

Avaliação dos impactos sociais, de custo/benefício e custo/eficácia do Programa Vira Vida (ciclo 2012 - 2014) 


\section{Introdução}

Desde 2008, o Conselho Nacional do Sesi (Consesi) vem implementando um programa multidisciplinar para mais de 3.500 adolescentes e jovens brasileiros. O Vira Vida proporciona serviços de assistência integral aos participantes, incluindo saúde, educação profissional, regular e continuada, treinamento profissional, inserção no mercado de trabalho e acompanhamento, como forma de reduzir a exploração sexual de adolescentes e jovens em 19estados da federação.

Como exposto no Plano Nacional de Enfrentamento da Violência Sexual Infanto-Juvenil (BRASIL, 2002),"[...] a violência sexual contra crianças e adolescentes é um fenômeno complexo e de difícil enfrentamento, inserido num contexto histórico-social de violência endêmica e com profundas raízes culturais". Foi apenas na década de 1990, com a aprovação do seu estatuto, que crianças e adolescentes passaram no Brasil a ser juridicamente considerados sujeitos de direitos e não mais como menores incapazes, objetos de tutela, de obediência e de submissão. Por isso, a avaliação dos impactos sociais, econômicos e financeiros do programa tem o importante papel de contribuir para a minimização dessa problemática, buscando pistas para o fortalecimento de projetos e políticas públicas para adolescentes e jovens submetidos a esse contexto.

A condição de explorado sexualmente envolve abuso sexual. Porém, essa exploraçãoabrangeviolência "[...] com fins comerciais e (que) tem como intermediário o aliciador pessoaquelucra com a venda dosexocom meninos e meninas" (ANDI, 2008). Essa definição foi originada no Congresso Mundial Contra a Exploração Sexual Comercial de Crianças e Adolescentes, realizado em Estocolmo, em 1996. Além disso, a exploração sexual comercial foi classificada em quatro modalidades: tráfico para fins sexuais, prostituição, turismo sexual e pornografia.

Esta avaliação foi independente e realizada entre 2012 e 2014, após aprovação em protocolo de pesquisa submetido a comitê de ética credenciado junto ao Conselho Nacional de Ética em Pesquisa (Conep) 6 . Foram entrevistados 1.227 adolescentes e jovens em 2014, em 18 estados e no Distrito Federal, divididos em quatro diferentes grupos, sendo três de caso, ou seja, que de alguma forma participaram do programa, e um de controle.

Nos tópicos a seguir, é apresentada a revisão da literatura que embasou a elaboração da escala de conhecimentos, atitudes e práticas e o questionário do estudo, os quais traduzem as transformações objetivadas pelo Vira Vida. Posteriormente são discutidos os principais impactos de equidade (sociais), de custo/benefício (econômicos) e de custo/eficácia (financeiros) obtidos, considerando ainda os limites do estudo, assim como suas conclusões e recomendações finais.

\section{Revisão de literatura}

A partir dos conceitos contidos nas metas e indicadores do objetivo geral do marco lógico foi feita uma profunda revisão de literatura científica, para que se pudesse chegar a uma 
primeira versão da escala de transformação do Vira Vida e, consequentemente, buscar um instrumento para se verificar como estariam os jovens atendidos pelo programa ao final de um ciclo de sua implementação.

A literatura sobre autonomia e efetividade dos direitos sociais e da cidadania associados aos jovens é bastante vasta nas diversas abordagens relacionadas ao desenvolvimento juvenil. A produção científica referente a esse assunto está vinculada ao desenvolvimento geral dos jovens e analisa uma série de variáveis que os afetam. Quatro domínios principais foram identificados durante o levantamento bibliográfico e convertidos nos principais domínios de variáveis da escala: 1) inserção no mundo do trabalho, 2) fortalecimento de vínculos familiares e comunitários, 3) independência econômica, e 4) autoestima. Cada um desses domínios contemplou uma série de variáveis, que podem ser testadas e aferidas para estabelecer sua correlação com os domínios principais levantados.
Antes de entrar nos domínios específicos, vale ressaltar os autores basilares para a construção da escala. Eles não são citados diretamente na matriz da escala a seguir, mas representam alicerces fundamentais do Programa Vira Vida: Paulo Freire, Antônio Carlos Gomes da Costa e Boaventura de Sousa Santos. Os princípios trabalhados por eles estão inseridos de forma inequívoca no programa. No caso de Freire, pela dimensão libertadora da educação focada na construção da autonomia e no envolvimento do estudante. Para o autor, a educação só existe quando forma comportamentos, e, por isso, ela é um ato político. Não porque faz política, mas porque, indissoluvelmente, está associada à reflexão. $\mathrm{E} o$ ato reflexivo é contra a despolitização, a desumanização, a alienação cultural e a favor da conscientização, que significa o começo da busca de uma posição de luta (1983 a, 1983 b). Freire é um dos autores mais pesquisados e citados no mundo quando o assunto é educação libertadora.

6 Protocolo aprovado e disponível para consulta sob o código P.I.EX, em dezembro de 2011, pelo Comitê de Ética em Pesquisa do Uniceub, fundamentado pela Resolução n 196 - que normatiza a pesquisa com seres humanos no Brasil - e pela Resolução do Conselho Federal de Psicologia No 016/2000, em particular suas recomendações específicas que abordam a pesquisa com populações vulneráveis. Neste caso, são os respondentes de 16 a 17 anos que possam ter sofrido ou sido submetidos à condição de abuso ou exploração sexual.

Revista Brasileira de Monitoramento e Avaliação | Número 9 | Janeiro-Junho de 2015 
Antônio Carlos Gomes da Costa (2006) foi o grande pioneiro nos estudos direcionados ao tema juventude e empreendedorismo. Para o autor, a formação do jovem deve estar pautada pela autonomia, moldada sempre pela solidariedade e pelo espírito empreendedor. Ele atuou em diversas frentes, inclusive na construção do Estatuto da Criança e do Adolescente (ECA), com participação no Comitê Internacional dos Direitos da Criança.

Por fim, Boaventura de Sousa Santos (2003) soube prever as bases da nova sociedade, a partir dos efeitos da globalização e da dinamização tecnológica, refletindo sobre a valorização da emancipação social, a justiça e a criatividade em um novo contexto social.

No domínio da inserção no mundo do trabalho, foram identificadas algumas variáveis relacionadas à autogestão, ao empreendedorismo e ao emprego formal, no nível de qualificação profissional. Entre essas variáveis se destacam a formação da identidade, a vulnerabilidade, a qualificação profissional, a capacidade para se integrar ao mercado de trabalho, a relação entre dinheiro e sustento, os preconceitos sofridos por jovens, a qualidade educacional, as condições sociais, a formalização das relações de trabalho, os espaços e oportunidades para a juventude, a orientação e a percepção de apoio social, a disposição emocional e a orientação para o mercado de trabalho. De acordo com Thomé et al, (2010), para muitos jovens, a experiência ou inexperiência de inserção no mercado laboral torna-se fator fundamental no processo de formação de sua identidade.

Com relação ao domínio de fortalecimento de vínculos familiares comunitários, as principais variáveis se referem a intervenções preventivas da comunidade, problemas externalizados, gratidão, atividades diárias, convivência familiar diária, pontos de apoio familiar, existência de conflitos e de violência na família, problemas de recursos financeiros na família, e problemas associados ao uso de drogas. Redmond et al, (2009) relaciona a proteção paternal com resultados de habilidades de jovens. Efeitos positivos de intervenção foram encontrados para os resultados dos jovens, dos pais e familiares (por exemplo, a associação com pares antissociais, gestão de crianças, qualidade afetiva entre pais e filhos) em cada ponto de avaliação pós-intervenção. Já para Burt e Roisman (2010), externar problemas afeta a competência acadêmica e social para internalizar problemas mais tarde.

Michale et al, (2009) analisou a importância das atividades diárias dos jovens, concluindo que elas podem ter impacto, uma vez que (a) oferecem oportunidades de aprender e praticar habilidades, (b) servem como fórum para o desenvolvimento da identidade, (c) possibilitam criar vínculos sociais, (d) conectam a juventude às instituições sociais, e (e) permitem aos jovens se dedicarem a outros tipos de atividades.Com relação às relações familiares, Edwards (Et al, 2009) destaca que prevenir problemas de comportamento em famílias e promover trajetórias positivas de desenvolvimento de crianças requerem a compreensão das necessidades e dos riscos dos membros da família e a identificação de seus pontos fortes, de apoio e de recursos. Neste aspecto, Diógenes (2008) analisou as consequências da violência intrafamiliar e concluiu que, nas narrativas dos sujeitos que foram alvo dessa modalidade de resolução 
de conflito, a violência é inaceitável e causa mágoas e ressentimentos capazes de quebrar laços familiares.

O domínio da independência econômica muitas vezes se refere à utilização dos recursos da bolsa de estudos. Neste domínio, as variáveis principais são assistência parental, dependência material, fontes de obtenção de renda, peso do recurso familiar, trabalho formal e informal, diferenças entre área urbana e rural, classe social e escolaridade. Também é influenciado pelo tempo de trabalho e pelo início da vida laboral. Swartz et al, (2011) observou que a assistência dos pais foi menos próxima para aqueles que fizeram mais progressos no caminho para a vida adulta, representada pela realização socioeconômica e formação. Já Schmidt (1990)destaca que a relação entre filhos maiores e pais não pode deixar de estar marcada pela grande dependência material destes em relação aos pais e a outros parentes.

Por fim, no construto de autoestima, relacionado à autoconfiança e à perspectiva de vida, são apresentadas as variáveis de relacionamento com pessoas, responsabilidades, problemas de externalização e internalização de problemas, competências acadêmicas e sociais, vínculos comunitários, sociais e escolares. Pode-se concluir que os projetos de desenvolvimento de habilidades têm grande importância. Vella et al, (2011) sugere que treinadores se veem como responsáveis por facilitar oito temas inter-relacionados e interdependentes consistentes com a literatura de desenvolvimento juvenil positivo: competência, confiança, conexão, caráter, habilidades para a vida, clima, afeto positivo e capacidades psicológicas positivas. Para O'Connor et al, (2011),relacionamentos de alta qualidade atuam como fatores de proteção, ajudando a impedir que crianças com altos níveis de comportamentos internalizantes na infância desenvolvam problemas de comportamento internalizantes de longo prazo.

Estudo realizado por Witherspoon et al, (2009) com modelos lineares hierárquicos mostraram que cada perfil de conexão foi significativamente associado com o autorrelato de adolescentes sobre séries, autoestima e sintomas depressivos, após o ajuste para variáveis correlacionadas, sugerindo que o domínio e o número de contextos são importantes para o desenvolvimento positivo da juventude.Por fim, Bruening et al, (2009) concluiu, com base em teorias de engajamento e aprendizado de cinco escolhas, que há uma relação entre a combinação de atividades físicas e esportivas, vida, habilidades e promoção de escolhas de vida saudáveis. Esses resultados refletiram-se nos seguintes temas: autoestima, autorresponsabilidade, conexões com comunidade, sensação de pertencimento, conhecimentos sobre saúde, habilidades de vida, aplicação dessas habilidades, planejamento e reconhecimento da influência sobre si mesmo e sobre os outros.

Revista Brasileira de Monitoramento e Avaliação | Número 9 | Janeiro-Junho de 2015 


\section{Metodologia e análise}

\subsection{PANORAMA METODOLÓGICO}

Os quatro grupos entrevistados no estudo foram os seguintes: 1) matriculados (jovens que à época da coleta estavam matriculados), 2) evadidos (jovens que foram matriculados, mas que, quando da coleta, não participavam mais do programa), 3) mercado (jovens que tiveram alguma experiência de mercado depois de formados no Vira Vida) e 4) controle (jovens de perfil socioeconômico similar, que não tiveram contato com o programa).

Alunos inseridos no programa a partir de $1^{\circ}$ de agosto de 2012 até o momento da coleta, em maio e junho de 2014, dentro dos grupos matriculados, evadidos ou mercado, fizeram parte do recorte de coleta. O principal objetivo da avaliação foi verificar possíveis impactos sociais, econômicos, e financeiros alcançados pelo Programa Vira Vida.

Depois de aprovado o protocolo em comitê de ética, o estudo contemplou mais quatro etapas: elaboração de marco lógico de avaliação; elaboração de instrumentos de pesquisa avaliativa; coleta de dados (método de grupo controle); e realização das análises financeira, econômica e social.
A análise financeira focou todos os aspectos da gestão do programa, a partir de seus custos, sua eficácia e sua eficiência. Já a análise econômica verificou se os investimentos realizados no Vira Vida trouxeram impactos econômicos para os jovens, suas famílias e para a sociedade. Por fim, a análise social avaliou se o programa teve êxito na redução de desigualdades sociais, a partir dos seus objetivos de transformação.

As principais hipóteses investigadas no estudo foram:

- Hipótese nula 1 (Ho1): o Vira Vida não está associado ao crescimento dos níveis de autonomia, cidadania e direitos sociais de adolescentes e jovens de 16 a 24 anos, participantes do programa.

- Hipótese nula 2 (Ho2):os níveis de autonomia, cidadania e direitos sociais não diferem entre os quatro grupos de adolescentes e jovens de 16 a 24 ano investigados: a) participantes do Programa Vira Vida; b) evadidos do programa; c) concluintes no programa que já se encontram inseridos no mercado de trabalho; e d) adolescentes e jovens que não se matricularam ou participaram do Vira Vida.

- Hipótese nula 3 (Ho3):a inserção de adolescentes e jovens de 16 a 24 anos concluintes do ViraVida no mercado de 
trabalho não está associada à sua participação no programa.

- Hipótese nula 4 (Ho4): não diferem os níveis de autonomia, cidadania e direitos sociais de adolescentes e jovens de 16 a 24 anos, participantes ou não do Vira Vida.

Todas as hipóteses foram nulas para que se atendesse ao principal requisito científico da avaliação: não seria possível verificar qualquer impacto do programa nas três análises sugeridas até que a metodologia proposta fosse utilizada para analisar impactos do programa na vida dos adolescentes e jovens participantes, de 16 a 24 anos, em condição de exploração sexual? .

\subsection{MARCO LÓGICO DE AVALIAÇÃO}

O primeiro passo foi definir os indicadores de impacto e de gestão do ViraVida em uma matriz de marco lógico, na qual se relacionaram objetivos, metas, indicadores, fontes de verificação, riscos, insumos, produtos e atividades investigadas. Essa etapa foi realizada com o apoio de mais de 20 representantes do Conselho Nacional do Sesi e parceiros do Vira Vida. Isso para que as variáveis e indicadores utilizados na avaliação pudessem representar a realidade do programa. Os elementos definidos para o marco lógico foram incluídos nos instrumentos da pesquisa, segunda etapa da avaliação.A seguir, parte da matriz de marco lógico ${ }^{8}$ construída para a avaliação.

\section{- MARCO LÓGICO AVALIATIVO DO PROGRAMA VIRA VIDA}

\begin{tabular}{lllll}
\hline $\begin{array}{l}\text { OBJETIVO GERAL } \\
\text { DO VIRAVIDA }\end{array}$ & METAS & INDICADORES & $\begin{array}{l}\text { MEIOS DE } \\
\text { VERIFICAÇÃO }\end{array}$ & RISCOS \\
\hline $\begin{array}{l}\text { Promover a autono- } \\
\text { mia e a efetivação } \\
\text { dos direitos sociais } \\
\text { e da cidadania, com } \\
\text { adolescentes e jovens } \\
\text { na faixa etária de } 16 \text { a } \\
24 \text { anos em situação de } \\
\text { exploração sexual }\end{array}$ & $\begin{array}{l}\text { 1) Garantir no mínimo } \\
80 \% \text { no índice de } \\
\text { autonomia nos ado- } \\
\text { lescentes e jovens }\end{array}$ & $\begin{array}{l}\text { 1.1) Inserção no } \\
\text { mundo do trabalho: } \\
\text { autogestão, empreen- } \\
\text { dedorismo e emprego } \\
\text { formal, nível de qualifi- } \\
\text { cação profissional }\end{array}$ & $\begin{array}{l}\text { Pesquisa avaliativa } \\
\text { com os jovens e ado- } \\
\text { lescentes participantes } \\
\text { (a ser construída) }\end{array}$ & $\begin{array}{l}\text { ção dos instrumentos } \\
\text { pelos jovens }\end{array}$ \\
\hline
\end{tabular}

7 A exploração sexual é a utilização sexual de crianças e adolescentes com a intenção do lucro, seja financeiro ou de qualquer outra espécie. Plano Nacional de Enfrentamento da Violência Sexual contra Crianças e Adolescentes. Secretaria dos Direitos Humanos, Conanda, maio de 2013.

8 Documento completo em anexo.

Revista Brasileira de Monitoramento e Avaliação | Número 9 | Janeiro-Junho de 2015 


\subsection{INSTRUMENTOS DE PESOQUISA}

Nessa etapa foram elaborados quatro instrumentos para a pesquisa avaliativa: a escala de transformação do programa, o questionário ambos necessários para a verificação do impacto de transformação nos adolescentes e jovens atendidos -,uma ferramenta para a coleta de dados de gestão dos 19 departamentos regionais (DRs) do Sesi participantes da avaliação e outra para verificação dos preços sombra dos itens adquiridos pelo programa.

Na literatura científica, as escalas CAP se referem a instrumentos para verificação de conhecimentos, atitudes e práticas, no plano social, ambiental ou cultural (KALIYAPERUMAL, 2004). Os domínios da escala do ViraVida representam os CAPs nos quais o programa concentra seus esforços de transformação.
Para construir a escala, foram realizados os procedimentos relatados a seguir.A partir dos conceitos contidos nas metas e indicadores do objetivo geral do marco lógico foi feita uma profunda revisão de literatura científica, para que se pudesse chegar a uma primeira versão da escala do projeto e, consequentemente, elaborar um instrumento para verificar o nível de transformação dos jovens nos quatro grupos investigados: evadidos, matriculados, controle e mercado.

Como demonstrado no item de revisão de literatura, as referências pesquisadas sobre esse assunto estavam vinculadas ao desenvolvimento geral dos jovens, incluindo um número considerável de variáveis que os afetam. Assim, na matriz inicial da escala, foram incluídas 90 variáveis, divididas em cinco diferentes domínios ou fatores.

\section{- escala: VERSÃo INICIAL (ANTES do PRÉ-TESTE)}

1. Inserção no mundo do trabalho: autogestão, empreendedorismo e emprego formal, nível de qualificação profissional (vari-
áveis 1 a 33)
2. Capacidade de fazer escolhas ( 34 a 45)
3. Fortalecimento de vínculos familiares comunitários ( 46 a 59)
4. Independência econômica (utilização dos recursos da bolsa de estudos) (variáveis 60 a 72 )
5. Autoestima: autoconfiança, perspectiva de vida, entre outros ( 73 a 90)


Cada um desses domínios trouxe uma série de variáveis, que foram testadas e aferidas para estabelecer sua correlação com os domínios principais levantados. Para tal, foi realizada a análise de validade e consistência da escala de transformação social do Programa ViraVida, a fim de possibilitar a efetivação de sua pesquisa avaliativa, para verificação de possíveis impactos.

Estabelecer a validade de uma escala pode se compreendido comodefinir parâmetros conceituais sobre aquilo que se quer medir, ou seja, é saber sobre aquilo que se está falando. "Somente quando concluímos que um estudo utiliza medidas válidas de seus conceitos-chave que teremos esperança de que suas conclusões serão válidas" (SCHUTT, 2004, p. 86). Já consistência significa queum procedimento de medição produz resultados fundamentados quando o fenômeno a ser medidonão está mudando (oua mudançados valores obtidos tem correspondência direta com as transformações reais no fenômeno) (SCHUTT, 2004). Porém, talvez o principal entendimento do conceito de consistência de uma variável ou um construto seja que ela serve como pré-requisito para análise de validade. Funciona como uma espécie de guia para os pesquisadores/gestores definirem as variáveis e construtos mais adequados e sua intercorrelação para a escala estudada.

Para que fosse possível realizar as análises de consistência, foi feita pré-testagem do questionário oriundo da escala em Brasília/DF, Recife/ $\mathrm{PE}$ e Rio de Janeiro/RJ, com 60 indivíduos de 16 a 24 anos, sendo 30 do grupo que participa do Vira Vida e 30 do grupo de controle, ou seja, não integrante do programa. Os indivíduos foram selecionados pelos próprios departamentos regionais do Sesi (DF, $P E, R J)$, parceiros do projeto, considerando os critérios de seleção para idade e intervenção/controle. Todos os casos de respondentes de 16 a 17 anos foram autorizados por seus responsáveis legais, a partir de termos de autorização assinados. Além disso, todos os respondentes assinaram termo de consentimento livre e esclarecido (TCLE).

De posse do banco de dados da pré-testagem, foram realizados os procedimentos de análise da validade e da consistência, junto aos gestores do Conselho Nacional do Sesi, chegando-se a uma escala final com quatro domínios e 65 variáveis. A análise fatorial mostrou que, além da consistência interna da escala total, aferida pelo alfa de Cronbach ${ }^{9}$ de 0,870 , realizada com o programa Stata 8.0, todos os quatro domínios da escala são consistentes: Domínio 1,0,663; Domínio

9 Alfa de Cronbach é um método popular de medição da confiabilidadepara, por exemplo, quantificá-la em uma pontuação ou escala para resumir as informações de diversos itens nos questionários(CHRISTMANN, VAN AELST, 2006).

Revista Brasileira de Monitoramento e Avaliação | Número 9 | Janeiro-Junho de 2015 
2,0,720; Domínio 3, 0,758; e Domínio 4,0,739. Todos esses valores de alfa de Cronbach são adequados, visto que o valor satisfatório considerado na literatura específica é 0,6.

Todas as variáveis têm pesos, para identificar as respostas mais positivas ou negativas em relação ao que se espera do jovem. Tome-se como exemplo a seguinte pergunta: trabalhar ajuda a formar o modo de agir e pensar das pessoas?Espera-seque os jovens participantes do Vira Vida respondam afirmativamente. Porém, as opções com tendência positiva, negativa ou neutra foram sempre apresentadas de forma equivalente, para não enviesar as possibilidades de resposta. Para cada opção foi dado um peso que variou de -1, para a pior resposta em relação ao domínio estudado, a +1 , para a melhor resposta. Assim aconteceu para as 65 variáveis componentes da escala, podendo gerar um somatório de +65 a -65 , conforme a tabela a seguir.

\section{- ESCALA FINAL DE TRANSFORMAÇÃO DO VIRA VIDA}

\begin{tabular}{lcc}
\hline DOMÍNIOS & $\begin{array}{l}\text { VALOR } \\
\text { PLENO }\end{array}$ & $\begin{array}{c}\text { VALOR } \\
\text { MÍNIMO }\end{array}$ \\
\hline Mundo de trabalho & 11 & -11 \\
\hline Educação & 16 & -16 \\
\hline $\begin{array}{l}\text { Vínculos familiares e } \\
\text { comunitários }\end{array}$ & 15 & -15 \\
Desenvolvimento humano & 23 & -23 \\
\hline TOTAL & 65 & -65 \\
\hline
\end{tabular}

Cada resposta gerou um valor, que foi somado ou retirado da variável seguinte, até a última questão. A seguir, exemplos das variáveis como foram incluídas no questionário final.

\section{- ESCALA FINAL DE TRANSFORMAÇÃO DO VIRA VIDA}

\begin{tabular}{|c|c|c|c|c|}
\hline VARIÁVEL/ QUESTÃO & DOMÍNIOS & $\begin{array}{l}\text { PESOS DAS } \\
\text { RESPOSTAS }\end{array}$ & $\begin{array}{l}\text { VALOR } \\
\text { PLENO }\end{array}$ & $\begin{array}{l}\text { VALOR } \\
\text { MÍNIMO }\end{array}$ \\
\hline $\begin{array}{l}\text { Trabalhar ajuda a forma o modo de } \\
\text { agir e pensar das pessoas? }\end{array}$ & $\begin{array}{l}\text { Inserção no mundo de } \\
\text { trabalho }\end{array}$ & $\begin{array}{l}\text { Sim: }+1 \\
\text { Não:-1 }\end{array}$ & 1 & -1 \\
\hline $\begin{array}{l}\text { Como você avalia o apoio recebido } \\
\text { pela comunidade em que você } \\
\text { vive? }\end{array}$ & $\begin{array}{l}\text { Vínculos familiares e } \\
\text { comunitários }\end{array}$ & $\begin{array}{l}\text { Ótimo: 1, Bom: 0,5, } \\
\text { Regular: 0. Ruim: }-0,5, \\
\text { Péssimo: }-1\end{array}$ & 1 & -1 \\
\hline $\begin{array}{l}\text { Como você avalia o seu } \\
\text { relacionamento com as pessoas? }\end{array}$ & $\begin{array}{l}\text { Autoestima, autono- } \\
\text { mia, perspectiva de } \\
\text { vida e outros }\end{array}$ & $\begin{array}{l}\text { Ótimo: 1, Bom: 0,5, } \\
\text { Regular: 0, Ruim: }-0,5, \\
\text { Péssimo: }-1\end{array}$ & 1 & -1 \\
\hline
\end{tabular}




\subsection{COLETA DE DADOS}

Os dados do estudo tiveram três fontes distintas: os jovens e adolescentes, os departamentos regionais (DRs) e o conselho nacional (CN), contando ainda com estabelecimentos de mercado, em alguns estados selecionados. Ao todo, o programa foi investigado em 19 estados e 23 cidades $^{10}$. No que tange aos jovens e adolescentes, as amostras coletadas seguiram o planejamento exposto no protocolo de pesquisa, totalizando 1.227 pessoas, compreendendo os grupos de alunos matriculados, evadidos, os já inseridos no mercado de trabalho e jovens do grupo de controle.

Para que fosse possível realizar esta coleta de dados foi feito um trabalho minucioso de convite dos potenciais respondentes pelos DRs. As maiores dificuldades estiveram nos seguintes pontos: obter a amostra de 25 respondentes evadidos por cidade, devido ao alto grau de vulnerabilidade destes jovens; localizar os respondentes do grupo de controle; obter os termos de consentimento livre e esclarecido assinados, assim como os termos de autorização dos responsáveis legais pelos entrevistados de 16 a 17 anos; fazer a busca da numeração de documentos dos entrevistados após o preenchimento; e interpretar algumas das marcações e escritas nos questionários. Os dados de gestão foram obtidos nos mesmos 19 estados e 23 cidades participantes da avaliação e abasteceram a análise financeira, como será visto a seguir. Por fim, as informações de mercado relativas ao preço sombra alimentaram a análise econômica, conforme também está expresso adiante.

\subsection{ANÁLISES DE IMPACTO}

No que tange à avaliação, os pontos de partida são a avaliação em si e a da modalidade impacto. Na perspectiva deste projeto, a avaliação deve ser tomada como primeiro passo do planejamento, a partir da definição dos indicadores, objetivos, metas e riscos que orientarão a gestão (FONTES, 2008a), diferentemente do monitoramento, que é contínuo, regular e ocorre durante a fase de implementação do projeto ou programa (UNFPA, 2004; OWEN, 2006). No caso da perspectiva de impacto avaliativo, o intuito é investigar o participante do programa fora do ambiente da intervenção, do meio de controle do projeto, na sua vida real, considerando a mudança de hábitos, comportamentos e estilos de vida (FONTES, 2001). Em outras palavras, levam-se em conta efeitos de longo termo, que perdurem na vida das pessoas.

\footnotetext{
10 Alagoas (Maceió), Amazonas (Manaus), Bahia (Salvador), Ceará (Fortaleza), Goiás (Goiânia), Maranhão (São Luís), Minas Gerais (Belo Horizonte e Montes Claros), Rio Grande do Norte (Natal), Pará (Belém), Paraíba (João Pessoa e Campina Grande), Pernambuco (Recife), Piauí (Teresina), Paraná (Curitiba, Foz do Iguaçu e Londrina), Rio de Janeiro (Rio de Janeiro), Rondônia (Porto Velho), Rio Grande do Sul (Porto Alegre), Sergipe (Aracaju), São Paulo (São Paulo), e o Distrito Federal.
}

Revista Brasileira de Monitoramento e Avaliação | Número 9 | Janeiro-Junho de 2015 
Para facilitar a leitura dos números dos 11 departamentos regionais do Sesi participantes do estudo, utilizou-se uma técnica estatística que coloca todos os números numa escala entre 0 e 1, em que " 0 " é a menor taxa de eficácia, e "1", a maior. Esta é a fórmula para cálculo do índice de desenvolvimento humano (IDH). O melhor DR no quesito estudado vira o padrão ouro da análise, com valor "1", máximo, em relação aos demais DRs que participam do estudo. Por outro lado, o DR com pior desempenho no quesito terá valor " 0 " relativamente aos outros. Todos os demais ficarão entre o padrão ouro e o padrão nulo. A fórmula abaixo, para o cálculo do subíndice de custo financeiro, orientou todos os subíndices e índices finais das análises financeira, econômica e social.Apenas as variáveis mudaram, não a fórmula, conforme demonstrado a seguir:

$S U B_{-} I N D I C E_{1}=1-\left[\frac{\text { custpess }-\operatorname{mín}(\text { custpess })}{\operatorname{máx}(\text { custpess })-\operatorname{mín}(\text { custpess })}\right]$ Onde:

custpess $=$ custo por pessoa

$\min ($ custpess $)=$ valor mínimo observado entre os $D R^{\prime}$ s do custo por pessoa máx(custpess $)=$ valor máximo observado entre os $D R^{\prime} s$ do custo por pessoa

Outro diferencial da avaliação de impacto foi a utilização de grupos de referência ou controle ${ }^{11}$, dentro da metodologia de caso controle, utilizada no estudo ${ }^{12}$. Esse grupo foi formado por adolescentes e jovens de 16 a 24 anos com o mesmo perfil socioeconômico dos participantes do ViraVida, mas que não foram submetidos à intervenção. Assim, os impactos do ViraVida puderam ser atribuídos somente ao programa com segurança estatística, sem a possível interferência de outras iniciativas.
O grupo de controle foi definido a partir dos cadastros de alunos que participaram do processo de seleção para participação no ViraVida. Meninas e meninos não selecionados pelo programa compuseram esse grupo. Os participantes do controle possuíam as mesmas características socioeconômicas, mas não necessariamente tinham passado por exploração sexual ou problemas considerados graves pelo uso de drogas lícitas e/ou ilícitas.

\subsection{ANÁLISE FINANCEIRA (CUSTOI EFICÁCIA/EFICIÊNCIA)}

Esta análise trata de reflexões sobre o padrão de qualidade do programa, suas práticas de gerenciamento e demais itens que devem estar sob o controle dos gestores e técnicos que planejam e realizam a intervenção. Em outras palavras, esta é a análise da gestão ou da oferta do Vira Vida. O objetivo é identificar de que forma as ações do programa podem alcançar maior eficácia com menor custo, a partir de seus pontos fortes e gargalos. Para se investigar o possível padrão de gestão do programa, utilizaram-se os objetivos, metas, indicadores, meios de verificação, riscos, insumos e produtos expressos no marco lógico de avaliação do programa, conforme já citado neste artigo.

O conjunto dos dados apresentados a seguir aponta para a existência de um padrão de gestão no ViraVida em todo o Brasil. Ainda que esse padrão esteja em construção, o estudo indica que ele facilitará o empreendimento de medidas gerenciais capazes de fortalecer ainda mais o programa. Custo, eficácia 
e eficiência foram contemplados em subíndices específicos, cuja média aritmética formou o índice final de custo/eficácia de cada DR. A seguir,são explicadas todas as categorias mencionadas.

\section{- Custo}

Na abordagem utilizada para este estudo, o custo representa o valor de todos os bens e serviços usados para a realização do programa durante um determinado período de tempo. É diferente do conceito de despesa, que nada mais é que o montante de recursos gastos num período de tempo, sem a preocupação com os produtos gerados (Hidalgo, 2003). O custo do programa é medido a partir da soma dos valores investidos para a sua realização, ou seja, os recursos financeiros disponibilizados pelo conselho nacional, verbas dos DRs e rateio. Esse valor foi dividido pelo número de alunos matriculados em 2013. e assim foi estabelecido o custo por jovem. Verificou-se que a média do custo financeiro anual por aluno foi de R\$ 23.687,85. Dividindo esse valor por 12 meses, período de um ciclo de funcionamento do programa, tem-se o custo financeiro mensal por aluno de $R \$ 1.973,99$. O custo financeiro total foi de $R \$ 25.787 .271,24$, incluindo valores do conselho nacional, dos departamentos regionais e de rateio (viagens, custos administrativos e outros).

\section{- Eficácia}

A eficácia mede o nível de realização dos resultados esperados.É a expressão do grau em que as atividades resultaram na resolução dos problemas identificados. Os resultados e os indicadores devem ser claramente definidos no começo, de modo que seja possível comparar o desempenho real ao que foi planejado (Schlesselman \& Stolley, 1982). Aeficácia de cada um dos DRs foi estabelecida a partir de 31 indicadores constantes do marco lógico do programa. Ou seja, foram determinados pisos percentuais ou numéri-

11 Um grupo de sujeitos que não recebe o tratamento experimental (a intervenção), mas em todos os outros aspectos é tratado da mesma forma que o grupo experimental (para isolar os efeitos do tratamento). Tradução livre de Introduction to Design and Analysis. Students Handbook. Keppel, Saufley \& Tokunaga. WH Freeman, 1992.

12 Estudos grupo controle, também chamados de estudos retrospectivos, seguem um paradigma que procede do efeito à causa. Indivíduos com uma condição ou doença particular (caso) são selecionados para comparação com indivíduos nos quais esta condição ou doença não existe (controle). Essas comparaçães dizem respeito a atributos - passados ou presentes - ou casos de exposição que sejam considerados relevantes para o aparecimento da condição ou doença sob estudo. Control Group Studies: Design, Conduct and Analysis. Tradução livre de Schlesselman \& Stolley. Oxford University Press, 1982.

Revista Brasileira de Monitoramento e Avaliação | Número 9 | Janeiro-Junho de 2015 
cos, não sendo necessário atingir 100\% em todas as metas. A eficácia é medida a partir da coerência entre o que foi estabelecido no planejamento e o efetivamente cumprido. A taxa média do nível de eficácia de cada DR é resultado da soma de todos os indicadores de eficácia do DR sobre o número total de indicadores. Nesta avaliação, a taxa média obtida a partir da eficácia dos DRs foi de 0,53. Ou seja, $53 \%$ de todas as metas estabelecidas para todos os 31 indicadores de gestão foram atingidas de forma eficaz.

\section{- Eficiência}

Para fins desta avaliação, aeficiência, ou eficácia do custo, expressa a relação entre resultados e recursos.A avaliação da eficiência incide sobre o processo de entrega (medida entre planejado e executado) e os recursos utilizados para atingir os resultados (Schlesselman \& Stolley, 1982). Depois de estabelecer os custos e a taxa de eficácia de cada um dos departamentos regionais é preciso quantificar o desempenho de cada DR. A perda de eficácia amplia o custo por aluno, pois significa que os valores gastos não se transformaram inteiramente na realização das metas propostas no marco lógico. A razão entre o custo por pessoa e a taxa de eficácia é chamada de eficiência, ou eficácia do custo. Verificou-se que a média da eficiência alcançada pelos DRs foi de45.465,15.

Esse não é um valor financeiro, mas sim um valor numérico geral resultado da divisão do custo pela eficácia. Quando se faz a relação entre o custo financeiro médio do aluno e o valor médio da eficácia, verifica-se que houve uma perda de $47 \%$ do custo/aluno, ou seja, na eficácia total.

R\$ 23.687,85 (custo financeiro médio por aluno por DR)

= 45.465,15(eficiência mé-

dia por DR) 0,53 (eficácia média por DR)

Para entender melhor a abordagem para o quesito eficiência, veja o exemplo a seguir:

DR1

10,00 (custo) = 20,00 (eficiência)

0,50 (eficácia)

DR2

20,00 (custo) $=20,00$ (eficiência)

1,00 (eficácia)

No exemplo acima, o DR2 possui o dobro do custo financeiro por aluno. Porém, também tem o dobro da eficácia. Dessa forma, o valor de eficiência permanece o mesmo. Quanto maior a eficácia, menor a perda dos recursos investidos. Essa tendência se verificou para diversos DRs atuando no programa. Sendo assim, nem sempre os DRs de menor custo por aluno foram mais eficientes do que aqueles com maior custo, em função de sua significativa eficácia.

\subsection{ANÁLISE ECONÔMICA (CUSTO/ BENEFÍCIO)}

Sobre a perspectiva geral das análises de custo/benefício, vale a citação de Shaffer (2010) 
na qualele afirma que este pode ser um poderoso método para melhorar os padrões das políticas públicas. Contudo, o autor também coloca que ainda há muito espaço para a aplicação e o desenvolvimento de inovações no campo das avaliações de custo/benefício. Nas palavras dele:

Benefit-Cost Analysis (BCA) is long-suffering. Few schools of public policy have dedicated courses on it. Policymakers would rather not engage with it (unless it yields favorable conclusions). It is often dismissed as either overly quantitative, heavily prescriptive, imprecise, or biased (or all of these). And it has a very limited presence in journals such as American Journal of Evaluation and makes almost no appearance in the top economics journals, despite its fundamental link to the principles of economic efficiency. $(2010,141)$.

Sintetizando o trecho, a análise de custo/ benefício ainda é terreno árduo. Poucas escolas oferecem cursos sobre o assunto, e os profissionais do ramo consideram ainda uma perspectiva excessivamente quantitativa, prescritiva, imprecisa e com demasiada carga de viés. Sequer é um tema regular, segundo o autor, nos principais jornais e outros periódicos econômicos.
Considerando-se a colocação de Shaffer como válida, o cenário fica ainda mais complexo quando se agrega a análise de custo/ benefício às áreas sociais, que também, como campo investigativo de retornos de investimento, têm vasto universo a ser explorado. Talvez se possa afirmar não haver estudos em âmbito nacional que relacionem diretamente os conceitos de custo/benefício e desenvolvimento humano. Internacionalmente, também parece não haver estudos que tenham trabalhado diretamente possíveis níveis de associação, influência ou determinação entre os termos. Essa característica fortalece a importância da investigação proposta na fundamentação do problema, nos objetivos geral, específicos e na justificativa.

Inicialmente, os principais autores que fundamentam, para efeito deste estudo, a investigação dos impactos de produtividade de programas sociais e políticas públicas são Gittinger (1982)13 - que avaliou o impacto econômico de projetos agrícolas -, Heckman (1999, 2003, 2005, 2007) - talvez o expoente maior nesta área, prêmio Nobel por seus estudos que relacionam educação na infância e produtividade e Fontes (2001, 2008a) - em âmbito nacional, com avaliações embasadas na vertente de

13 Gittinger (1982) ainda aprofundou os principais elementos da análise de benefício que foram tratados nesta investigação: preço sombra, custo/benefício, valor presente líquido, taxa interna de retorno e razão custo/benefício, além das taxas de desconto e outros fatores de depreciação a serem utilizados.

Revista Brasileira de Monitoramento e Avaliação | Número 9 | Janeiro-Junho de 2015 
custo/benefício (2008b, 2011),abordando os impactos econômicos da mudança de comportamento na produtividade. Para o Banco Mundial (2010), a análise de custo/benefício pode fornecer uma visão abrangente do impacto líquido de projetos e ajudar a direcionar fundos diretos para onde a eficácia é mais elevada.

Autores complementares sobre o tema são Selameab e Yeh (2008), Resende e Willie (2006), e Menezes et al, (2005). Todos os autores citados apontam a renda familiar e a pessoal como variáveis de produtividade. Apenas Fontes (2011) trabalhou, em relatório específico de avaliação econômica de programa, a utilização do presenteísmo e do absenteísmo como medidas válidas para tal.

As análises realizadas mostram que o Vira Vida é um investimento social sólido e de qualidade. Cada R\$ 1,00 investido gerou 0 retorno médio de R\$ 1,74 para a sociedade brasileira, considerando todos os alunos que se mantiveram no programa no período 2013/2014. Foi possível determinar a riqueza gerada pelo Vira Vida ao se medir em reais quanto o programa rende para a sociedade e como os alunos formados serão reconhecidos pelo mercado de trabalho a partir da transformação gerada pelo programa.Os dados analisados compreendem o período 2013/2014 (até o mês de junho), nos 19 DRs participantes. A seguir, são explicados os procedimentos e componentes utilizados para se chegar aos valores de retorno.

\section{- Custo econômico}

Em um primeiro momento, foi preciso determinar o custo econômico da ação, ou seja, ajustar o custo financeiro total do programa pelos fatores "custo oportunidade" - todo o recurso não financeiro aplicado ao programa capaz de agregar valores aos custos dos serviços -e "preço sombra" - diferenciação entre o preço de mercado e o praticado pelos DRs na aquisição dos insumos necessários à realização do Vira Vida. O custo econômico bruto total foi de $R \$ 30.862 .464,60$, praticamente RS 5 milhões a mais do que o custo financeiro total. Para se chegar ao custo líquido econômico total, empregou-se a taxa de 4,28\%, chegando-se ao valor de R\$ 29.595.765,83. Dividindo o valor total pelo total de alunos formados, o custo econômico líquido médio por aluno foi de R\$33.403,80.

A taxa de 4,28\% foi utilizada como referência a partir do estudo de Lopez (2008), que chegou a esse dado a partir do estudo de alguns dos principais programas sociais realizados por nove países latino-americanos, inclusive o Brasil. Essa referência foi a mesma utilizada para se chegar aos benefícios econômicos líquidos, como será visto à frente. Essa taxa vem sendo utilizada para verificação de impactos econômicos em todas as avaliações do Banco Mundial para a América Latina.

\section{- Benefício econômico}

A etapa seguinte quantificou o benefício econômico obtido por cada aluno formado pelo 
programa, até chegar ao benefício líquido total. Tomaram-se apenas os alunos formados para que o modelo de cálculo fosse o mais conservador possível, isto é, reduzindo ao máximo a verificação dos possíveis benefícios econômicos realizados pelo Vira Vida. Caso fossem incluídos os alunos matriculados, os resultados ficariam sujeitos a críticas sobre a maximização dos impactos.

Em primeiro lugar, foi calculado o valor presente líquido (VPL) do Vira Vida, que também pode ser entendido como a riqueza produzida pelo programa em valor presente. O cál- culo do VPL é feito em partes. Inicialmente, as análises de regressão mostram que a influência da renda pessoal do jovem é significativa para a composição da renda familiar. Para cada $\mathrm{R} \$ 1,00$ a mais na renda do jovem, R\$0,78 vão compor a renda familiar. O programa também apresenta um impacto significativo na renda dos formados. O aumento fica na média de $\mathrm{R} \$ 351,73$ na renda pessoal mensal em relação ao grupo controle. Isso representa um incremento de renda de aproximadamente $122 \%$ logo após a inserção no mercado de trabalho. No entanto, esse impacto pode ser ainda maior ao longo do tempo.

\begin{tabular}{|c|c|c|c|c|c|}
\hline LINEAR REGRESSION & & & & & NUMBER OF OBS = \\
\hline \multicolumn{6}{|l|}{1194} \\
\hline & & & & & $F(3,18)=$ \\
\hline \multicolumn{6}{|l|}{14.61} \\
\hline & & & & & Prob $>F=$ \\
\hline \multicolumn{6}{|l|}{0.0000} \\
\hline & & & & & R-squared = \\
\hline \multicolumn{6}{|l|}{0.0999} \\
\hline Number of clusters (estado) $=19$ & & & & & Root MSE = \\
\hline \multicolumn{6}{|l|}{375.37} \\
\hline RENDAPESSOAL INTERVAL & COEF. & $\begin{array}{l}\text { ROBUST } \\
\text { STD. ERR. }\end{array}$ & $\mathrm{T}$ & $\mathrm{P}>|\mathrm{T}|$ & [95\% CONF. \\
\hline Evadido & -4.851596 & 54.43746 & -0.09 & 0.930 & -119.2205 \\
\hline \multicolumn{6}{|l|}{109.5173} \\
\hline Matriculado & 149.7396 & 46.30248 & 3.23 & 0.005 & 52.4617 \\
\hline \multicolumn{6}{|l|}{247.0175} \\
\hline Mercado & 351.731 & 58.02294 & 6.06 & 0.000 & 229.8294 \\
\hline \multicolumn{6}{|l|}{473.6327} \\
\hline Controle & 288.0001 & 41.3116 & 6.97 & 0.000 & 201.2077 \\
\hline 374.7926 & & & & & \\
\hline
\end{tabular}

Revista Brasileira de Monitoramento e Avaliação | Número 9 | Janeiro-Junho de 2015 
- MEAN OF RENDAPESSOAL1

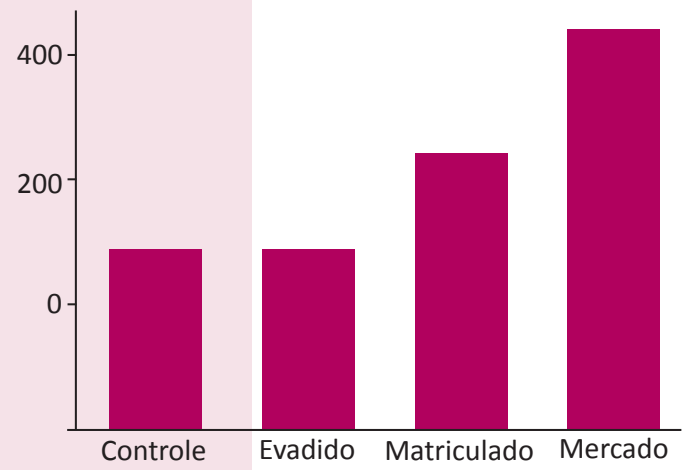

Visando estabelecer uma projeção econômica com alto valor científico, o presente trabatho considerou diversos descontos capazes de reduzir os benefícios gerados pelo programa. Para tanto, foi utilizada uma fórmula de descontos baseada no modelo de projeção de Gittinger (1982). Além da taxa de 4,28\% já mencionada, os outros fatores de desconto utilizados para os cálculos de custo e benefício foram a taxa de sobrevivência média no Brasil (20 a 59 anos), de 0,824, e a taxa de emprego no Brasil, de 0,908. No que tange à taxa de desconto de empregabilidade, nem todos os respondentes estavam empregados no momento da entrevista. A condição é que já tivessem se empregado depois de formados pelo Vira Vida. Esse dado está compreendido no fator de desconto de empregabilidade, já que, na projeção, as chances de se estar empregado ao final do ciclo produtivo, isto é, da carreira profissional média, serão sempre menores que $100 \%$. Incluindo todos os descontos, o benefício médio líquido por aluno foi de $R \$ 57.957,78$.

Para calcular ovalor presente líquido (VPL) total, faz-se o seguinte cálculo:
- Benefício econ. líquido total - custo econômico líquido total = VPL total

- $\quad R \$ 51.350 .594,71-R \$ 29.595 .765,83=$ RS 21.754.828,88

Esse valor já inclui todos os descontos do modelo de análise e representa a riqueza total produzida pelo programa no período 2013/2014, para todo o Brasil, em valor presente líquido, projetado para um ciclo produtivo de 40 anos.Por fim, para se chegar ao valor de 1,74, apresentado no início do tópico, basta dividir o benefício econômico líquido total pelo custo econômico líquido total. Para cada $\mathrm{R} \$ 1,00$ investido no Vira Vida, tem-se o retorno de $R \$ 1,74$.

\subsection{ANÁLISE SOCIAL (EQ̣UIDADE)}

A análise social do Vira Vida teve como objetivo verificar o possível impacto do programa na redução das diferenças sociais, caracterizadas pelas transformações produzidas em termos de valores do mundo do trabalho; valores educacionais; dos vínculos familiares e comunitários; e do desenvolvimento humano. Todas são dimensões da escala de valores do programa. A análise verificou se o programa produziu variações significativas nos domínios citados e nos níveis da escala como um todo, em relação aos quatro grupos investigados: evadidos, matriculados, controle e mercado. Além disso, averiguou se houve redução da diferença nos níveis da escala para os recortes de gênero, orientação sexual, dependência química e escolaridade. Isso quer dizer basicamente o seguinte: o posicionamento na escala dos participantes do sexo feminino, não heterossexuais, de pior escolaridade e que já foram ou são dependentes químicos 
é pior do que o dos meninos, heterossexuais, de escolaridade mais elevada e que não foram dependentes químicos. As possíveis diferenças em relação à vulnerabilidade medida na escala foram verificadas para cada um dos quatro recortes. O índice de Hoover (1984) foi utilizado para medir o efeito produzido pelo programa.

\section{- IV- IMPACTO VERIFICADOTI - FORTE TENDÊNCIA DE IMPACTON - NEUTRALIDADEIN - IMPACTO NEGATIVO}

\begin{tabular}{|c|c|c|c|c|c|}
\hline & & IMPACTOS SOCIAI & IS DO PROGRAMA VIRAV & IDA & \\
\hline $\begin{array}{l}\text { UNIDADE DE } \\
\text { ANÁLISE }\end{array}$ & $\begin{array}{l}\text { DOMÍNIO 1: } \\
\text { MUNDO DO } \\
\text { TRABALHO }\end{array}$ & $\begin{array}{l}\text { DOMÍNIO 2: EDU- } \\
\text { CAÇÃO }\end{array}$ & $\begin{array}{l}\text { DOMÍNIO 3: VÍNCU- } \\
\text { LOS COMUNITÁRIOS E } \\
\text { FAMILIARES }\end{array}$ & $\begin{array}{l}\text { DOMÍNIO 4: } \\
\text { DESENVOLVIMENTO } \\
\text { HUMANO }\end{array}$ & $\begin{array}{c}\text { ESCALA } \\
\text { TOTAL }\end{array}$ \\
\hline Brasil & & & $\mathrm{N}$ & & \\
\hline Alagoas & & & $\mathrm{N}$ & & \\
\hline Amazonas & & & N & & \\
\hline Bahia & $\mathrm{N}$ & N & N & N & $\mathrm{N}$ \\
\hline Ceará & & & $\mathrm{N}$ & & \\
\hline Distrito Federal & & $\mathrm{N}$ & N & & $\mathrm{N}$ \\
\hline Goiás & & & N & & \\
\hline Maranhão & $\mathrm{N}$ & & $\mathrm{TI}$ & & \\
\hline Minas Gerais & & TI & $\mathrm{N}$ & & \\
\hline Pará & & & N & & \\
\hline Paraíba & & N & N & & $\mathrm{TI}$ \\
\hline Pernambuco & & N & N & & \\
\hline Piauí & & & N & & \\
\hline Paraná & & N & $\mathrm{N}$ & $\mathrm{N}$ & $\mathrm{N}$ \\
\hline Rio de Janeiro & & IN & $\mathrm{N}$ & $\mathrm{N}$ & $\mathrm{N}$ \\
\hline $\begin{array}{l}\text { Rio Grande do } \\
\text { Norte }\end{array}$ & & & $\mathrm{N}$ & N & $\mathrm{N}$ \\
\hline Rondônia & & & $\mathrm{TI}$ & & \\
\hline $\begin{array}{l}\text { Rio Grande do } \\
\text { Sul } \\
\end{array}$ & $\mathrm{N}$ & $\mathrm{N}$ & $\mathrm{N}$ & N & $\mathrm{N}$ \\
\hline Sergipe & & & N & & $\mathrm{N}$ \\
\hline São Paulo & & $\mathrm{N}$ & $\mathrm{N}$ & $\mathrm{N}$ & $\mathrm{N}$ \\
\hline
\end{tabular}

Fonte: autores.

Revista Brasileira de Monitoramento e Avaliação | Número 9 | Janeiro-Junho de 2015 
Duas principais hipóteses foram estabelecidas para aferir o impacto da intervenção em nível nacional e estadual (19 estados):

- Hipótese 1: o programa está associado a um impacto na absorção de valores domundo do trabalho; educacionais;vínculos familiares e comunitários; e desenvolvimento humano.

- Hipótese 2:o programa está associado a um impacto na redução das diferenças sociais em função de gênero, escolaridade, dependência química e orientação sexual.

Na tabela acima são apresentados os principais resultados em nível nacional em relação à primeira hipótese. A legenda IV mostra os impactos atingidos em cada nível e que tiveram significância estatística (valor-p<0,05); na legenda TI estão as fortes tendências de impacto atingidas em cada nível (0,05>valor-p<0,1); na legenda $N$ estão os resultados que não apresentam impacto relevante ou forte tendência de impacto; e a legenda IN mostra os coeficientes negativos que tiveram significância estatística (valor-p < 0,05).

O Vira Vida conseguiu, em âmbito nacional,aumentar significativamente e atingir impacto em termos de valores do mundo do trabalho,educação e desenvolvimento humano. Pode-se afirmar que alterar a condição de vínculos familiares e comunitários dos participantes representa um desafio significativo na comparação com os outros três domínios da escala. A vivência e os maus-tratos característicos da exploração sexual parecem ser, de fato, uma barreira extremamente árdua de ser transposta. De um lado, fica claro que, no ambiente do programa, os participantes se sentem mais felizes, confiantes e menos vulneráveis, chegando até à empregabilidade. Porém, nos ambientes familiares e comunitários estão os desafios de transformação do Vira Vida. Vale dizer que, de qualquer forma, mesmo na dimensão de vínculos familiares e comunitários, não foi observada tendência de impacto negativo ou impacto negativo propriamente dito.

Já para a segunda hipótese, em relação ao impacto na redução das desigualdades sociais em função de gênero, escolaridade, dependência química e opção sexual, chegaram-se aos resultados apresentados na tabela a seguir levando-se em consideração a aferição de redução das diferenças na absorção dos valores desenvolvidos pelo programa. A legenda IV apresenta a capacidade do programa de neutralizar diferenças sociais (valor$-p>0,05)$, e a legenda $\mathrm{N}$ mostra as unidades que não conseguiram esse objetivo (valor$-p<0,05)$. Em alguns casos, não foi possível investigar a neutralização de diferenças sociais em função de um dos grupos de comparação ter $n<10$ indivíduos. 


\section{- IV- IMPACTO VERIFICADON - NEUTRALIDADE $\mathrm{N}<10$ - AMOSTRA INSUFICIENTE}

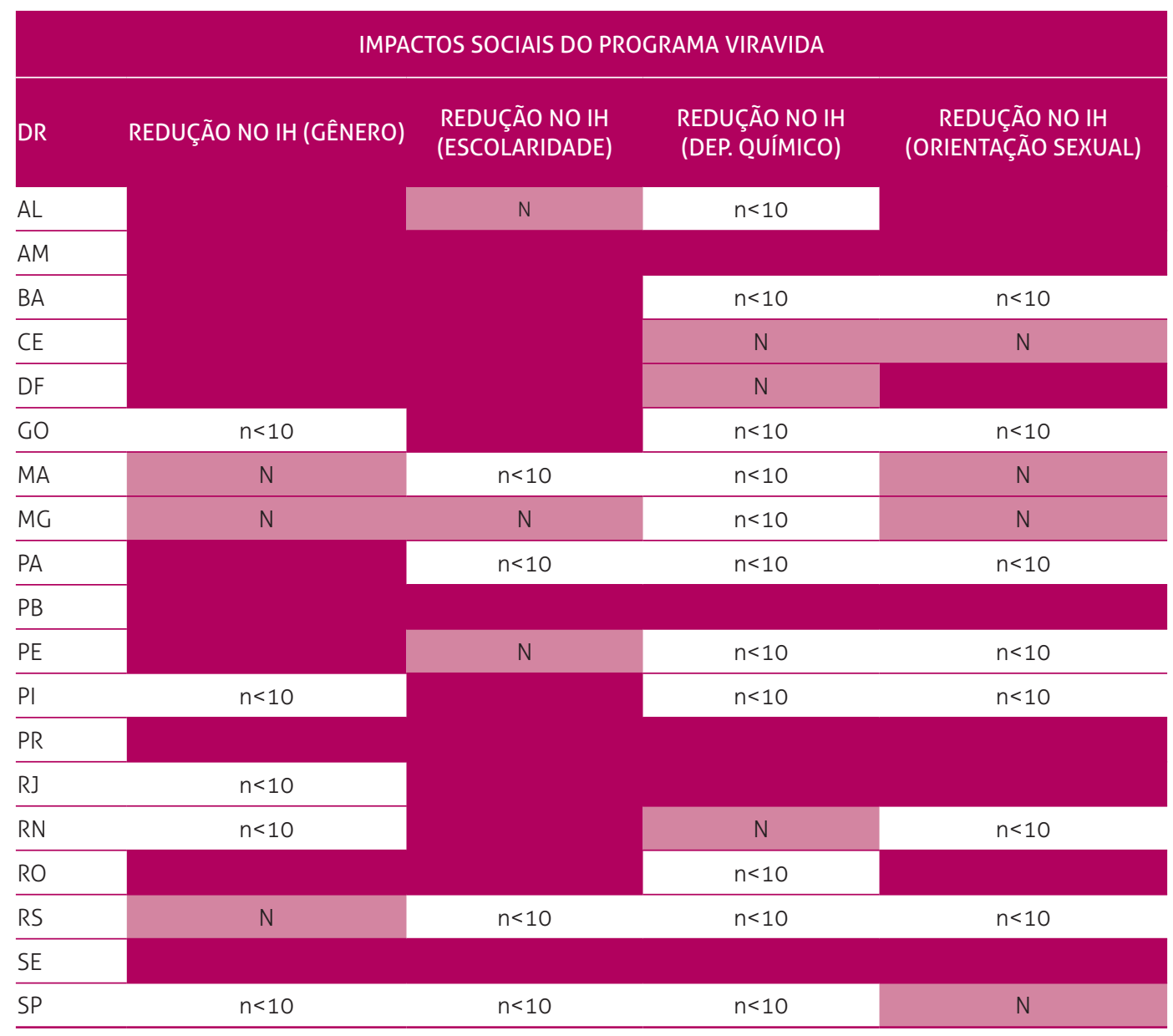

Fonte: autores.

A grande maioria dos estados brasileiros teve êxito em reduzir as diferenças sociais na escala de valores para gênero. Isso quer dizer que as meninas, após participar do programa, reduzem a distância para os meninos no que tange às transformações objetivadas pelo Vira Vida. Nos recortes de escolaridade, dependência química e orientação sexual, mui- tos estados também obtiveram este impacto. Os jovens de menor escolaridade, que já foram ou são dependentes químicos ou que não são heterossexuais conseguem chegar mais próximos do nível de transformação presente nos jovens de maior escolaridade, que nunca foram dependentes químicos e que são heterossexuais.Novamente, em nenhuma

Revista Brasileira de Monitoramento e Avaliação | Número 9 | Janeiro-Junho de 2015 
das variáveis foi observada forte tendência de impacto negativo ou impacto negativo propriamente dito.

\section{Limitações do estudo}

Os adolescentes e jovens de 16 e 17 anos, por serem população menor de idade, tiveram procedimentos especiais para a realização do estudo ${ }^{14}$. O principal foi a autorização de mãe, pai ou outro responsável legal mediante assinatura de termo específico, conforme apresentado no item de pesquisa avaliativa. Nesse sentido, é possível que esse segmento possa ter respondido ao questionário com algum tipo de pressão ou influência direta ou indireta não notada pelos pesquisadores no ato do pré-teste e não verificada pelos avaliadores ao trabalharem a base de dados.

Além disso, espera-se continuar monitorando e avaliando os impactos do programa ao longo do tempo. A opção inicial de coleta de caso controle se beneficiará de uma coleta ex post clássica. Essa opção se deveu ao fato de não ser possível fazer uma coleta experimental antes de um ciclo avaliativo do Vira Vida e outra depois. Assim, foram definidos quatro grupos de análise (evasão, mercado, matriculados e controle), para que as informações advindas de apenas um procedimento de coleta pudessem alimentar mais análises entre os grupos. No entanto, vale lembrar que os participantes dos quatro grupos tiveram chances equivalentes de responder ao estudo e, assim, dar viabilidade científica aos coeficientes considerados significantes de transformação.
As opções de método de coleta de dados foram definidas entre duas possibilidades: 1) a realização de uma avaliação de impacto clássica, com coleta antes (experimental antes/ex ante) e depois (experimental depois/ex post) do ciclo avaliativo de 2011 - incluindo grupo controle; ou 2) a realização de um caso controle, método que permite a elaboração de apenas uma coleta de dados. Após a consideração de vários aspectos, definiu-se a utilização do caso controle Ambos os métodos possuem qualidade similar, pois se entende que são igualmente significativos para verificar o "delta", isto é, a diferença entre o grupo que recebe o ViraVida e o que não participa do programa, em relação aos conhecimentos, atitudes e práticas em que o ViraVida foca seu intento de transformação.

O método clássico necessitaria de dois momentos de coleta de dados, o que exigiria prazos e recursos não disponíveis pelo programa, especialmente pela decisão de se usar grupo de controle. Já o caso controle funciona com apenas uma coleta, necessitando de menos recursos e tempo e dando mais prazo para as análises, reporte e estudo para o Conselho Nacional do Sesi decidira melhor forma de apresentação dos resultados às partes interessadas. Além disso, o caso controle é mais inclusivo, porque funciona também com dados retrospectivos, ou seja, com jovens que já tinham participado do programa antes da coleta, principalmente nos grupos de alunos evadidos e de mercado. No caso do método clássico (ex ante e ex post), haveria uma baseline, mas seria necessário entrevistar apenas os participantes do ciclo 2012-2014. 
Assim, a qualidade equivalente nos resultados do método clássico, a inclusão de mais potenciais respondentes participantes do programa e a realização de coleta única, reduzindo prazos e investimentos destinados à avaliação de impactos, foram motivos que justificaram a definição do método de caso controle para a avaliação de impacto do Vira Vida.

\section{Conclusões e recomendações}

As análises realizadas forneceram pistas importantes que permitem caracterizar o programa como um investimento social cientificamente validado. Os modelos de pesquisa e avaliação utilizados mostraram-se robustos, quanto à modelagem de coleta e análise, e conservadores, quanto aos impactos verificados. Os dados aqui demonstrados permitem aos gestores do Programa Vira Vida fortalecerem seu posicionamento institucional junto às partes interessadas, no âmbito nacional e nos estados participantes.

O simples custo financeiro por aluno participante inverte toda a lógica de tratamento de adolescentes e jovens em estado avançado de vulnerabilidade, saindo de uma perspecti- va de gastos para redução de danos - como é feito com meninos e meninas infratores - para uma dimensão de lucro social. O custo médio por aluno para um ciclo completo de atendimento integral não chega a R\$ 2.000,00/mês, enquanto os gastos com internação prisional de adolescentes e jovens podem passar de R\$7.000,00/mês (Castro, 2004)(valores de 2004). Considerando-se a inflação, o custo com internaçãohoje passaria dos R\$ $10 \mathrm{mil}$ mensais, em uma estrutura com baixos índices de recuperação e reinserção familiar e comunitária.

O ViraVidapossui um padrão de gestão nacional, considerando os 19estados analisados, sem DRs significativamente acima ou abaixo dos outros. Porém, ainda tem um ótimo espaço para crescimento. Nesse aspecto, a criação e a utilização de sistemas de gestão padronizados podem trazer resultados positivos. Dinâmicas de discussão com os DRs sobre os dados desta avaliação podem fortalecer novos planejamentos e ciclos de gestão do Vira Vida nos estados e nacionalmente. Além disso, deve-se considerar que a sistematização da tecnologia social do programa, em processo de finalização, poderá auxiliar para a consolidação de um padrão de gestão nacional.

14 Resolução Conselho Nacional de Saúde (CNS) n. 196/96, Item IV 3. À época, a resolução vigente que orientava as submissões de protocolos de pesquisa em comitês de ética vinculados ao Conep.

Revista Brasileira de Monitoramento e Avaliação | Número 9 | Janeiro-Junho de 2015 
No plano de equidade, vale ressaltar que o Vira Vida reduziu desigualdades sociais na inserção dos jovens no mundo do trabalho, aumentou os valores educacionais e impactou o desenvolvimento humano, mas deve ampliar esforços no fortalecimento de vínculos familiares e comunitários. Esse aspecto está relacionado diretamente com a perspectiva de gestão, objeto da análise financeira. Assim, nos próximos planejamentos e avaliações nacionais e regionais, os indicadores referentes a esse domínio da escala precisam ser observados e fortalecidos ao máximo.

A razão benefício/custo de 1,74 permite dizer que os adolescentes e jovens formados pelo programa são cidadãos $74 \%$ mais produtivos para o mercado de trabalho e para a vida plena em sociedade. Já a riqueza econômica líquida total produzida pelo programa foi de RS 21.754.828,88.0 importante, nesse sentido, é discutir e trabalhar possíveis ganchos e materiais customizados com os gestores de comunicação, vinculando-os aos objetivos de utilização dos dados e adequando-os às partes interessadas.

Os impactos auferidos na realização das análises financeira, econômica e social podem fortalecer o Vira Vida no seu posicionamento com stakeholders e catalisar o processo de transformação do programa em política pública nacional. Se ganhar escala e mantiver o padrão de atuação, o Vira Vida poderá se consolidar como um dos investimentos sociais mais significativos do país, promovendo uma nova dimensão de crescimento e sustentabilidade econômica, social e humana. 


\section{Referências bibliográficas}

BRASIL. Secretaria dos Direitos Humanos; Conselho Nacional de Defesa dos Direitos da Criança e do Adolescente. Plano Nacional de Enfrentamento da Violência Sexual contra Crianças e Adolescentes. 2002. Disponível em: $<$ http://www.comitenacional.org.br/files/anexos/08-2013_PNEVSCA-2013_f19r39h.pdf>. Acesso em: 15 de maio de 2014.

BRASIL. Secretaria dos Direitos Humanos; Consetho Nacional de Defesa dos Direitos da Criança e do Adolescente. Plano Nacional de Enfrentamento da Violência Sexual Infanto-Juvenil. Relatório de Monitoramento 2003-2004. Brasília: SEDH/DCA, 2006,

BRUENING, J. E., DOVER, K. M., CLARK, B. S. Preadolescent Female Development Through Sport and Physical Activity: a case study of an urban after-school program. Research Quarterly for Exercise and Sport, v. 80, n. 1, p. 87-101, 2009.

BURT, K. B. \& ROISMAN, G. I. Competence and psychopathology: Cascade effects in the NICHD Study of Early Child Care and Youth Development. Development and Psychopathology, v. 22, n.3, p.557-567, 2010.

CASTRO, A. O Primeiro Passo. Revista Desafios do Desenvolvimento, n. 4. Brasília: IPEA - Instituto de Pesquisa Econômica Aplicada, 1/11/2004.

CHRISTMANN, A. e VAN AELST, S. Robust estimation of Cronbach's alpha. Journal of Multivariate Analysis, v. 97, n. 7, p. 1660-1674, agosto 2006.
CONSELHO FEDERAL DE PSICOLOGIA. Resolução No 016/2000. Disponível em: <http://www.assis. unesp.br/Home/ComitedeEtica/ComitedeEticaHumanus1346/resolucao_CFP_16-2000_-_dispoe_sobre_pesquisa_com_seres_humanos.pdf $>$. Acesso em: 22 de março de 2014.

CONSELHO NACIONAL DE SAÚDE (CNS). Resolução n. ${ }^{\circ}$ 196/96. Disponível em: <http://conselho.saude.gov.br/Web_comissoes/conep/aquivos/resolucoes/23_out_versao_final_196_ENCEP2012.pdf>. Acesso em: 12 de agosto de 2013.

DIÓGENES, G. Os sete sentimentos capitais: exploração sexual comercial de crianças e adolescentes. São Paulo: Annablume, 2008.

EDWARDS, O. W.; TAUB, G. E. A Conceptual Pathways Model to Promote Positive Youth Development in Children Raised by Their Grandparents. School Psychology Quarterly, v. 24, n. 3, p. 160-172, 2009.

FONTES, M. Metodologia de Avaliação de Impacto Social (MAIS). Metodologia registrada na Fundação Biblioteca Nacional (Ministério da Cultura) sob o No 312.152; Livro:569; folha: 312. 2001.

FONTES, M. Marketing Social. Novos Paradigmas. São Paulo/SP: Elsevier, 2008.

FREIRE, P. Educação e Mudança. Rio de Janeiro: Paz e Terra, 1983.

FREIRE, P. Educação como Prática da Liberdade. Rio de Janeiro: Paz e Terra, 1983.

Revista Brasileira de Monitoramento e Avaliação | Número 9 | Janeiro-Junho de 2015 
GITTINGER. J. P. Economic Analysis of Agricultural Projects. The Johns Hopkins University Press. Maryland, USA, 1982.

GOMES DA COSTA, A. C.; VIEIRA, M. A. Protagonismo Juvenil. São Paulo: Editora FTD, 2006.

HECKMAN J. J., LALONDER. J., SMITH, J. A. The economics and econometrics of active labor market programs. Handbook of Labor Economics, v. 3, pate A, p. 1856-2097, 1999.

HECKMAN J. J.; LOCHNER, L.; TODD, P. Fifty years of Mincer earnings regressions. Institute for the Study of Labor (IZA), 2003. ( Discussion Paper, $\mathrm{n}^{0775)}$ ).

HECKMAN, J. J. Structural Equations, Treatment Effects, and Econometric Policy Evaluation. Econometrica, v. 73, n. 3, p. 669-738, May 2005.

HECKMAN, J. J.; LEAMER, E. L. Handbook of Econometrics, v. 6. North-Holland, 2007.

HIDALGO, L. J., Logical Approach to Project Management in PAHO. Pan American Health Organization, 2003.

HOOVER, E. M. Jr.; An Introduction to Regional Economics, 1984.

KEPPEL, SAUFLEY; TOKUNAGA W. H. FREEMAN, Introduction to Design and Analysis. Students Handbook. 1992.

LOPEZ, H. The Social Discount Rate: Estimates for Nine Latin American Countries. Banco Mundial, 2008. (Policy Research Working Paper 4639).
MENEZES, W. F., CARRERA-FERNANDEZ, J.; DEDEC$C A, C$. Diferenciações Regionais de Rendimentos do Trabalho: Uma Análise das Regiões Metropolitanas de São Paulo e de Salvador. Est. Econ., São Paulo, v. 35, n. 2, p. 271-296, abril-junho 2005.

MICHALE, S. M., DOTTERER, A.; KIM, J. Y. 2009. An Ecological Perspective on the Media and Youth Development. American Behavioral Scientist, v. 52, n. 8, p. 1186-1203, 2009.

O'CONNOR, E. E.; DEARING, E.; COLLINS, B. A. Teacher-Child Relationship and Behavior Problem Trajectories in Elementary School. American Educational Research Journal, v. 48, n. 1, p. 120-162, 2011.

REDMOND, C. et al. Long-term protective factor outcomes of evidence-based interventions implemented by community teams through a community-university partnership, Journal of Primary Prevention, 2009.

RESENDE, M., E WILLIE, R. Retornos para a Educação no Brasil - evidências empíricas adicionais. Econ. aplic., São Paulo, v. 10, n. 3, p. 349-365, julho-setembro 2006.

SCHLESSELMAN \& STOLLEY. Control group Studies: design, conduct and analysis. Oxford, University Press, 1982.

SCHUTT, R. K. Investigating the social world: the process and practice of research. Thousand Oaks: Pine Forge Press, Sage Publications, 2004. 
SANTOS, B. de S. Pela Mão de Alice. O Social e o Político na Pós-Modernidade. São Paulo: Cortez Editora, 2003.

SCHMIDT, Luísa 1990. Jovens: família, dinheiro, autonomia. Análise Social, v. 25, n.4 e 5, p. 645673, 1990.

SELAMEAB, T. E YEH, S. S. Evaluating Intangible Outcomes: Using Multiattribute Utility Analysis to Compare the Benefits and Costs of Social Programs. American Journal of Evaluation. Sage Publications, p. 29:301, 2008.

SHAFFER, M. Multiple Account Benefit-Cost Analysis: a practical guide for the systematic evaluation of project and policy alternatives. Toronto, Canada: University of Toronto Press, 2010.

SWARTZ, T. T. et al. Safety Nets and Scaffolds: Parental Support in the Transition to Adulthood. Journal of Marriage and Family, v. 73, n. 2, p. 414-429, 2011.

THOMÉ, L. D.; TELMO, A. Q.; KOLLER, S. H. Inserção laboral juvenil: contexto e opinião sobre definições de trabalho. Paidéia, Ribeirão Preto, v. 20, n.46, p. 175-185, 2010.

VELLA, S., OADES, L.; CROWE, T. The Role of the Coach in Facilitating Positive Youth Development: Moving from Theory to Practice. Journal of Applied Sport Psychology, v. 23, n. 1, p. 33-48, 2011.
WEISS, M. R. 2011. Teach the Children Well: A Holistic Approach to Developing Psychosocial and Behavioral Competencies Through Physical Education. Quest, v. 63, n. 1, p. 55-65, 2011.

WELLER, W. Grupos de discussão na pesquisa com adolescentes e jovens: aportes teórico-metodológicos e análise de uma experiência com o método. Educação e Pesquisa, São Paulo, v.32, n.2, p. 241260, maio/ago. 2006.

WITHERSPOON, D. et al. 2009. Connecting the Dots: How Connectedness to Multiple Contexts Influences the Psychological and Academic Adjustment of Urban Youth. Applied Developmental Science, v. 13, n. 4, p. 199-216, 2009.

Websites Acessados:

Website oficial do Programa Vira Vida. www.viravida.org.br

AGENCIA DE NOTÍCIAS DOS DIREITOS DA INFÂNCIA (ANDI). Guia de Cobertura da Agência de Notícias dos Direitos da Infância, 2008. http:// www.redeandibrasil.org.br/eca/guia-de-cobertura/exploracao-sexual. acessado em 17 de abril de 2014.

Childhood Brasil. Glossário:http://www.childhood.org.br/entenda-a-questao/glossario\#A; e http://www.childhood.org.br/entenda-a-questao/ glossario\#E, acessado em 22 de abril de 2014. 